\title{
Associations between two nursing workload scales and the cost of intensive care unit nursing staff: A retrospective study of one Belgian hospital
}

\author{
Arnaud Bruyneel RN, CCN, Msc ${ }^{1,2}$ | Julie Maes RN, CCN, MSc ${ }^{3,4}$ | \\ Lionel Di Pierdomenico RN, MSc ${ }^{1,5}$ | Jérôme Tack RN, CCRN, Msc ${ }^{1,2,4}$ | \\ Martin Bogaert Msc ${ }^{1}$ ｜ Pol Leclercq MD, PhD ${ }^{1}$ | Magali Pirson RN, PhD ${ }^{1}$
}

${ }^{1}$ Health Economics, Hospital Management and Nursing Research Department, School of Public Health, Université Libre de Bruxelles, Brussels, Belgium

${ }^{2} \mathrm{SIZ}$ Nursing, A Society of Intensive Care Nurses, Belgium

${ }^{3}$ Simulation Laboratory for Healthcare Professions, SimLabS, Faculty of Medicine, Université Libre de Bruxelles, Brussels, Belgium

${ }^{4}$ Department of Intensive Care, Erasme Hospital, Université Libre de Bruxelles, Brussels, Belgium

${ }^{5}$ Medical Information Department, $\mathrm{CHU}$ Charleroi Marie-Curie, Charleroi, Belgium

\section{Correspondence}

Arnaud Bruyneel, Health Economics, Hospital Management and Nursing Research Department, École de Santé Publique Campus Erasme, Bâtiment A Route de Lennik 808, Brussels CP591 1070, Belgium. Email: arnaud.bruyneel@ulb.be

\begin{abstract}
Aims: The aim of this study was to assess associations between a general nursing funding scale and an intensive care unit specific nursing workload scale and the cost of nursing staff.

Background: Nurse staffing represents the most important cost in the intensive care unit, so it is essential to evaluate it accurately. In addition, the assessment of nursing workload is important for the daily management of the intensive care unit and to ensure quality of care.

Methods: This was a retrospective and quantitative study carried out in the intensive care unit of a Belgian hospital. The extraction of data from the Nursing Activities Score and the Minimum Hospital Summary Nursing Dataset were carried out during 2 periods of 15 days, from 1 June 2018 to 15 June 2018 and from 1 September 2018 to 15 September 2018.

Results: A total of 234 patients were included in the study. A total of 773 Nursing Activities Score and Minimum Hospital Summary Nursing Dataset recordings were analyzed in the study per intensive care unit day. A strong correlation was observed between Nursing Activities Score and Minimum Hospital Summary Nursing Dataset for the entire intensive care unit stay with a rho $(95 \% \mathrm{Cl})$ of $.88(0.83-.93)$; however, the correlation was moderate per intensive care unit day with a rho of .51 (0.450.57). A strong association was observed between the Minimum Hospital Summary Nursing Dataset and the Nursing Activities Score with the costs of intensive care unit nurses with a rho $(95 \% \mathrm{Cl})$ of $.78(0.72-0.86)$ and $.74(0.65-0.84)$, respectively.

Conclusions: A general nursing funding scale in Belgium was strongly correlated with the nursing workload for the whole intensive care unit stay, but this correlation was moderate per intensive care unit day. In contrast, both scales showed a good correlation with intensive care unit nursing costs.

Implications for nursing management: In Belgium, a general funding scale for nurses does not allow for an assessment of the nursing workload in the intensive care unit.
\end{abstract}


The Nursing Activities Score is strongly correlated with the cost of nursing staff in the intensive care unit. The authors recommend that the Belgian authorities carry out this type of study in several intensive care units in the country and eventually replace the general funding scale for nurses with the Nursing Activities Score.

\section{KEYWORDS}

care organisation, cost, hospital funding, nursing activities score, workload

\section{1 | BACKGROUND}

The cost of caregivers is the most important cost factor in intensive care units (ICUs) (Bittner et al., 2013) (Reis Miranda \& Jegers, 2012) (Kilic et al., 2019). One study conducted in four European countries estimated the cost of an ICU to be around $20 \%$ of total hospital direct costs, of which about half is spent on nurse staffing (Tan et al., 2012). However, high nurse workload in the ICU is associated with nursesensitive patient outcomes (Driscoll et al., 2018) and an increased risk of burnout (Bruyneel et al., 2021). In addition to producing better results, costs avoided due to fewer readmissions and shorter length of stay have been demonstrated with provision of additional nursing staff (McHugh et al., 2021; Murphy et al., 2021). Therefore, an accurate analysis of the operating costs associated with human resources is necessary within an ICU to determine whether resources are properly allocated according to the individual needs of patients and to avoid understaffing or overstaffing the ICU workforce (Ricci de Araújo et al., 2021; Stafseth et al., 2018).

In Belgium, hospital funding is still mixed. Part of the funding is financed by the budget of financial means (37.3\%), which is linked to the activity of the hospital and evaluated by the diagnosis-related group, and the remainder of the funding comes from medical acts (39.8\%), pharmaceutical products (18.4\%) and conventions (4.5\%) (Durant et al., 2021). The financing of nursing care, including that of intensive care nurses, comes from part of the budget of financial means (40\%) and is adjusted according to the nursing activity Minimum Hospital Summary Nursing Dataset (MHSND) (Pirson et al., 2013). This scale is encoded only four times a year for 2 weeks for all patients hospitalized in Belgium, and it is not specific to the ICU. The MHSND is a minimal tool for recording nursing interventions performed and not a recording of all of the care provided to the patient or the care required by the patient. This tool is used both to provide a minimum collection of data on nursing interventions carried out and to finance the nursing staff. Nevertheless, the effectiveness of this scale in the ICU has never been evaluated (Stephani et al., 2018).

In other European countries, the funding of nursing uses intensive care-specific workload scales such as the Simplified Therapeutic Intervention Scoring System (TISS-28) and the Nine Equivalents of Nursing Manpower Use Score (NEMS) (Reis Miranda \& Jegers, 2012). According to a literature review, these scales are used in Germany, Great Britain and Austria (Bittner et al., 2013). To our knowledge, the Nursing Activities Score (NAS) (Miranda et al., 2003) is not yet used for the official funding of ICU nursing, although it is the most accurate scale to assess nursing workload in the ICU (Greaves et al., 2018; Hoogendoorn et al., 2020). In addition, the NAS is suitable for estimating the cost of ICU nursing per stay, a factor that may be of interest to hospital managers (Oliveira et al., 2019; Stafseth et al., 2018).

The aim of this study was to assess associations between the MHSND and the NAS in intensive care and the cost of nursing staff.

\section{2 | METHODS}

\subsection{Design and setting}

This was a retrospective and quantitative study carried out in the ICU of a Belgian university hospital consisting of four ICUs with a total of 32 medico-surgical beds, including six paediatric beds. The recording and extraction of data from the NAS and the MHSND were carried out during two periods of 15 days, from 1 June 2018 to 15 June 2018 (Period 1) and from 1 September 2018 to 15 September 2018 (Period 2).

\section{2 | Instrument and data collection}

The NAS covers $81 \%$ of nursing activities involving care for the patient (Category 1 ) and is independent of disease severity. In addition, the nurses spent about $6 \%$ of their time performing activities not directly related to patient care and not medical (Category 2) and about $11 \%$ on personal activities of the nurse (Category 3 ). The activities that could not be scored in the activities of the other categories (Category 4) represented $2 \%$ of nursing time (Miranda et al., 2003). This retrospective scale specific to intensive care can be encoded by shift or by day ( $24 \mathrm{~h})$. This tool has been validated in 99 ICUs from 15 countries and is included in a large number of international publications. Composed of 23 items, it includes both direct and indirect care. Each item representing a nursing activity is subject to a binary choice (for 18 items) or multiple choice (for 5 items). The score (per patient) is expressed as a percentage and varies from $0 \%$ to $177 \%$. This represents the average proportion of nursing time needed to provide care to the patient $(100 \%=1$ nurse). The weighting of the items was done according to the 'worksampling' method, which is a reliable method resulting from industrial engineering, making it possible to measure action times without the inconvenience of timing. This scale provides an approach to nursing workload that measures the nursing time consumed per patient. 
The NAS scale used in this study has been translated, and adapted to Belgium, for use by shift. This version of the scale was published in a previous study by Bruyneel et al. and validated by Professor Miranda (author of the NAS scale) (Bruyneel et al., 2018). The score was encoded via a computer tool (Epimed Monitor ${ }^{\circledR}$ ) at the end of each shift by nurses at the bedside. In our sample, nurses worked either in three shifts, mainly $8 \mathrm{~h}$ in the morning, $8 \mathrm{~h}$ in the afternoon or $11 \mathrm{~h}$ at night. The score was encoded as soon as the patient was admitted to the unit until discharge. The NAS is weighted in minutes per day based on the patient's time in the ward. Because $100 \%$ corresponds to $24 \mathrm{~h}$ of a nurse's working time, $1 \%$ is equivalent to $14.4 \mathrm{~min}$ (Miranda et al., 2003; Padilha et al., 2015). The NAS is not yet used to fund nurses in the ICU. However, workload scales as the Therapeutic Intervention Scoring System-28 and the NEMS are already used in Germany, Austria and the United Kingdom (Bittner et al., 2013).

Concerning the MHSND, the last official version is from 2017, coding manual MHSND 2.0, composed of 62 items structured into six groups: (1) care related to basic physiological functions; (2) complex physiological functions; (3) behavior; (4) safety; (5) family and relatives; and (6) health care management (Myny et al., 2014). The development of the items was based on the international Nursing Interventions Classification. A study carried out in 2013 made it possible to obtain a standard time per item, expressed in minutes, as TimeSkill Points using a Delphi method (Sermeus et al., 2007; SPF Santé publique, 2017). This scale is only used in Belgium. However, the same methodology for constructing the scale (Delphi method) has been used for other scales such as the Projet de Recherche en Nursing and Leisungserfassung in der Pflege (Myny et al., 2014).

Concerning the cost analysis, these data were obtained from a hospital cost analysis project conducted by the research centre in Health Economics, Hospital Management and Nursing Research Department of the School of Public Health at the Université Libre de Bruxelles in Belgium, which calculated the cost of inpatient stays for 17 Belgian hospitals in 2018 (Pirson \& Leclercq, 2014). The allocation of nursing care costs in the ICU was made according to two criteria. The first one is based on the OMEGA scale, which uses some medical activities and care performed at the patient's bedside (Utilisation de l'indice de gravité simplifié et du système Omega, 1986). This scale, created in France and composed of 47 items, was adapted to Belgium, for activities usually recorded in the ICU. Following this, 21 items (40 Belgian activities) and 4 drug classes (12 ATC [Anatomical Therapeutic Chemical] codes) have been considered. Originally, the Omega scale was not intended to assess nursing workload but to allocate hospital costs. As suggested in one study, the score was not directly used for the nursing care cost allocation, and an Omega Score-related healing minutes was preferred (Blin et al., 1990). The second criterion is the length-of-stay (LOS) in the ICU. According to a consensus of experts, a 50/50 ratio between these two criteria has been used for the nursing care cost allocation.

Concerning the training level of the nurses in the study, in Belgium, we have two levels of training (bachelor's degree and no bachelor's degree) as well as a specialization, which takes place after the bachelor with an additional year that includes training in intensive and emergency care. Approximately $70 \%$ of the ICU nurses are specialized, logistics assistants and care assistants are present in a majority of the ICUs but only in the morning shift (Bruyneel et al., 2021; van den Heede et al., 2019).

\section{3 | Statistical analysis}

For comparisons of asymmetric variables, the Mann-Whitney $U$ and Kruskal-Wallis $H$ tests were used. For symmetric variables, Student's $T(t)$ test and the Chi-square test $\left(\chi^{2}\right)$ were used for proportion comparisons. Statistical analyses were performed with Software for Statistics and Data Science (14.0, Texas). A $p$ value $<.05$ was considered statistically significant. Means and standard deviations (SDs) were used to describe symmetric variables, and medians (Mdns) and InterQuartile Ranges (IQRs) were used to describe asymmetric variables.

For correlation analysis, Pearson's coefficient was used for symmetric data, and Spearman's Rank-Order (rho) was used for asymmetric variables. The interpretation of correlation in this study follows the references in this article (Schober et al., 2018).

\section{$2.4 \quad$ Ethical approval}

This study was approved by the University Libre de Bruxelles ethics committee. The data collected have been anonymized. Only the patient stay numbers were used to compare the data between the different MHSND and NAS databases.

\section{3 | RESULTS}

\section{1 | Socio-demographic characteristics}

This study included 234 patients with 119 patients in Period 1 and 115 in Period 2. The median (IQR) LOS in the ICU was 2 days (2) and was 10 days (11) for the entire hospitalization. The mean (SD) of Simplified Acute Physiology (SAPS) 3 was 46.3 (15.6), and the proportion of ventilated patients was $36 \%$. The most common type of admission was medical (51\%), followed by elective surgical (35\%) and urgent surgery (14\%). The most common category of pathology was cardiac surgery (21\%) followed by neurosurgery $(12 \%)$ and neurology (12\%). Finally, ICU mortality was $6 \%$, and hospital mortality was $12 \%$. No significant difference was observed between the two periods (Table 1).

\section{2 | NAS, MHSND and cost descriptions}

The mean (SD) NAS by $24 \mathrm{~h}$ was $65.5 \%$ (14.8) for the morning, $63.6 \%$ (17.3) for the afternoon, $60.5 \%$ (15.9) for the night and $70.3 \%$ (17.0) for $24 \mathrm{~h}$. A total of 773 NAS and MHSND activities were analyzed in 
the study per ICU Day. Regarding the NAS, converted to minutes per day, the median (IQR) was 712 (511), whereas the MHSND was 814 (340) min. MHSND minutes were also higher for the stay set than the NAS with 1776 (1528) and 1289 (1411), respectively. The median cost at the ICU per stay was $2915 €$ (4886) and $1306 €$ (2383) for the nursing cost nursing per stay in the ICU (Table 2).

\section{3 | Analysis of correlations between NAS and MHSND}

A very strong correlation was observed between NAS and MHSND for the entire ICU stay with a rho $(95 \% \mathrm{Cl})$ of .88 (0.83-0.93). In contrast, the correlation was moderate per ICU day with a rho of .51 (0.45-0.57) (Figure 1).
Regarding the factors for the entire stay, the strongest correlation was found in patients who had urgent surgery with a rho of .97 (0.90-0.99), and the weakest correlation was in medical patients with a result of .78 (0.71-0.93). For the analysis by ICU day, the strongest correlation was for patients present in Period 2 with a rho of .60 (0.54-0.67) and the weakest for patients who had urgent surgery with .29 (0.14-0.45) (Table 3).

\subsection{Analysis of correlations between the scores and cost}

A strong association was observed between the MHSND and the NAS with the cost of nurses in the ICU with a rho $(95 \% \mathrm{Cl})$ of .78 (0.72-0.86) and .74 (0.65-0.84), respectively (Figure 2).

TA B LE 1 Socio-demographic characteristics of the patients

\begin{tabular}{|c|c|c|c|c|c|}
\hline Characteristics & Period $1(n=119)$ & Period $2(n=115)$ & Test values & $p$ value & Total $(n=234)$ \\
\hline Age, mean $\pm S D$, y & $63.17 \pm 17.1$ & $59.2 \pm 18.1$ & $t=1.92$ & .054 & $61.5 \pm 17.7$ \\
\hline Paediatric case (>15 years), $n$ (\%) & $4(3)$ & $2(2)$ & $\chi^{2}=0.61$ & .443 & $6(3)$ \\
\hline Length of stay in ICU, median (IQR), d & $2(3)$ & $2(3)$ & $U=0.71$ & .477 & $2(2)$ \\
\hline Length of stay prior ICU, median (IQR), d & $1(2)$ & $1(2)$ & $U=1.39$ & .164 & $1(2)$ \\
\hline SAPS 3 , mean \pm SD & $47.7 \pm 14.9$ & $41.9 \pm 16.2$ & $t=1.40$ & .161 & $46.3 \pm 15.6$ \\
\hline Ventilated patients, $n$ (\%) & $42(35)$ & $43(37)$ & $\chi^{2}=0.47$ & .375 & $85(36)$ \\
\hline \multicolumn{6}{|l|}{ Type admission, $n(\%)$} \\
\hline Medical & $62(52)$ & $57(49)$ & $\chi^{2}=0.27$ & .873 & $119(51)$ \\
\hline Elective surgery & $41(35)$ & $40(35)$ & & & $81(35)$ \\
\hline Thoracic surgery & $13(11)$ & $7(6)$ & & & $20(9)$ \\
\hline Digestive surgery & $12(10)$ & $6(5)$ & & & $18(8)$ \\
\hline Vascular surgery & $7(6)$ & $8(7)$ & & & $15(6)$ \\
\hline Neurosurgery & $13(10)$ & $14(12)$ & & & $27(12)$ \\
\hline Neurology & $13(11)$ & $14(11)$ & & & $27(12)$ \\
\hline Cardiology & $11(9)$ & $13(11)$ & & & $24(10)$ \\
\hline Pneumology & $5(4)$ & $11(10)$ & & & $16(7)$ \\
\hline Sepsis & $14(13)$ & $6(5)$ & & & $20(9)$ \\
\hline Home & $2(2)$ & $3(2)$ & & & $5(2)$ \\
\hline Hospital mortality, n (\%) & $12(11)$ & $13(12)$ & $\chi^{2}=2.43$ & .384 & $15(12)$ \\
\hline
\end{tabular}

Abbreviations: d, days; ICU, intensive care unit; IQR, InterQuartile Range; SAPS 3, The Simplified Acute Physiology Score; SD, standard deviation; y, years. 
TAB LE 2 NAS, MHSND and cost descriptions

\begin{tabular}{|c|c|c|c|c|c|}
\hline Characteristics & Period 1 & Period 2 & Test values & $p$ value & Total \\
\hline NAS morning, mean $\pm S D, \%-n=636$ & $65.3 \pm 14.6$ & $65.2 \pm 15.1$ & $t=0.07$ & .963 & $65.3 \pm 14.8$ \\
\hline NAS afternoon, mean $\pm S D, \%-n=605$ & $62.0 \pm 16.2$ & $65.9 \pm 18.2$ & $t=-2.16$ & .030 & $63.6 \pm 17.2$ \\
\hline NAS $24 \mathrm{~h}$, mean $\pm S D, \%-n=773$ & $70.2 \pm 16.0$ & $70.6 \pm 18.2$ & $t=-0.26$ & .794 & $70.3 \pm 17.0$ \\
\hline NAS $24 \mathrm{~h}$ per day, median (IQR), min & $764(488)$ & $681(518)$ & $U=1.97$ & .072 & $712(511)$ \\
\hline Difference per day (MHSND-NAS), median (IQR), min & 99 (459) & $116(334)$ & $U=-0.60$ & .543 & $105(401)$ \\
\hline NAS $24 \mathrm{~h}$ per stay, median (IQR), min & $1570(1361)$ & $1107(1426)$ & $U=1.31$ & .189 & $1289(1411)$ \\
\hline MHSND per stay, median (IQR), min & $1885(1784)$ & $1627(1568)$ & $U=1.81$ & .069 & $1776(1528)$ \\
\hline Difference per stay (MHSND-NAS), median (IQR), min & $596(736)$ & $388(615)$ & $U=1.68$ & .091 & $479(702)$ \\
\hline Cost of the stay at the ICU, median (IQR), $€$ & 3314 (3948) & $2851(5477)$ & $U=0.57$ & .571 & $2915(4886)$ \\
\hline
\end{tabular}

Abbreviations: ICU, intensive care unit; IQR, InterQuartile Range; MHSND, Minimum Hospital Summary Nursing Dataset; NAS, Nursing Activities Score; $\mathrm{SD}$, standard deviation.
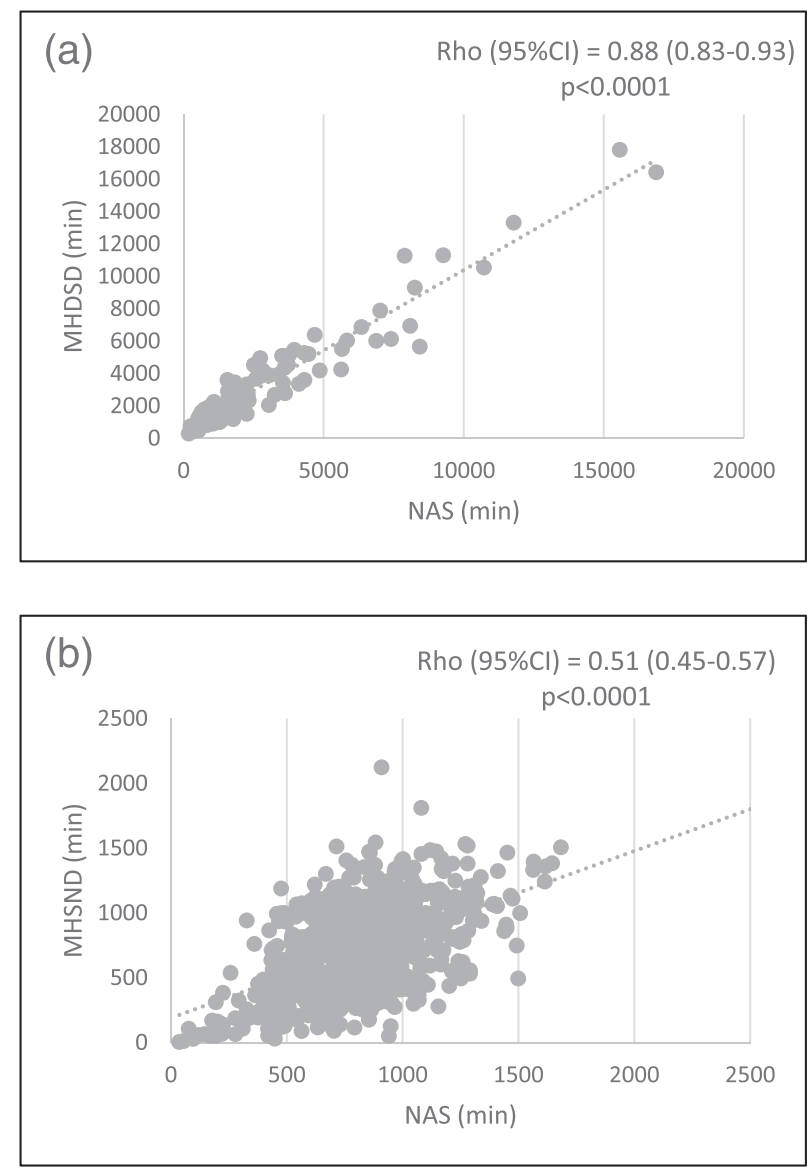

F I G U R E 1 Correlation between Nursing Activities Score (NAS) and Minimum Hospital Summary Nursing Dataset (MHSND). (a) Per stay; (b) per day

Regarding associated factors, the worst correlation was observed in geriatric patients with a rho .59 (0.69-0.90), and this was higher for urgent surgical patients with $.83(0.58-0.99)$ for the MHSND scale. For NAS, the same trend was observed with .48 (0.36-0.60) in geriatric patients and $.84(0.66-0.87)$ in urgent surgical patients (Table 4).

\section{4 | DISCUSSION}

In this study, the socio-demographic data, with mean (SD) SAPS 3 of 46.3 (15.6) and an ICU mortality rate of 6\%, correspond to other studies published in ICUs in Belgium (Bruyneel et al., 2019; Debergh et al., 2012).

The NAS results per shift and per $24 \mathrm{~h}$ are also consistent with a Belgian multicenter study published in 2019 (Bruyneel et al., 2019). With a median NAS converted into minutes per day of 712 (511), it is very similar to the MHSND minutes of 814 (340). However, there is a greater difference in minutes for the whole stay with a median NAS of 1289 (1411) and 1776 (1528) for MHSND. However, this difference can be explained by the high variability of ICU stays given the high IQR and high medians.

Regarding correlation analyses, a strong correlation was observed between the NAS and the MHSND for the whole stay with a rho (95\% Cl) of .88 (0.83-0.93). However, this correlation is moderate per ICU day with a rho of .51 (0.45-0.57) and possibly weak for some stays such as emergency surgery with a rho of .29 (0.14-0.45). The MHSND is not specific to the ICU, and it cannot determine the daily workload because it varies during the patient's stay in the ICU (Bruyneel et al., 2019) (Lucchini et al., 2014). In addition, the MHSND may not be able to identify high NAS, such as in patients undergoing urgent surgery such as cardiac surgery, or those with a high ICU length of stay (Lucchini et al., 2014). The MHSND, therefore, makes it possible to evaluate the cost of nursing staff for the entire stay but does not make it possible to evaluate the nursing workload in the ICU. However, the analysis of this workload is important in the daily 
TAB LE 3 Correlations between NAS and MHSND per day and per stay, rho $(95 \% \mathrm{Cl})$

\begin{tabular}{|c|c|c|c|c|}
\hline Characteristics & Per day & $p$ value & Per stay & $p$ value \\
\hline Period 1 & $.43(0.35-0.51)$ & $<.0001$ & $.88(0.82-0.94)$ & $<.0001$ \\
\hline Period 2 & $.60(0.54-0.67)$ & $<.0001$ & $.87(0.78-0.95)$ & $<.0001$ \\
\hline Male & $.48(0.41-0.56)$ & $<.0001$ & $.92(0.87-0.97)$ & $<.0001$ \\
\hline Female & $.55(0.470 .63)$ & $<.0001$ & $.80(0.69-0.91)$ & $<.0001$ \\
\hline Patients ventilated & $.34(0.24-0.45)$ & $<.0001$ & $.80(0.71-0.89)$ & $<.0001$ \\
\hline Medical & $.40(0.28-0.51)$ & $<.0001$ & $.78(0.64-0.93)$ & $<.0001$ \\
\hline Elective surgery & $.63(0.57-0.69)$ & $<.0001$ & $.91(0.86-0.95)$ & $<.0001$ \\
\hline Urgent surgery & $.29(0.14-0.45)$ & $<.0001$ & $.97(0.90-0.99)$ & $<.0001$ \\
\hline Paediatric patient & $.31(0.15-0.46)$ & $<.0001$ & $.97(0.90-0.99)$ & .0620 \\
\hline
\end{tabular}

Abbreviations: LOS, length of stay; SAPS 3, The Simplified Acute Physiology Score.

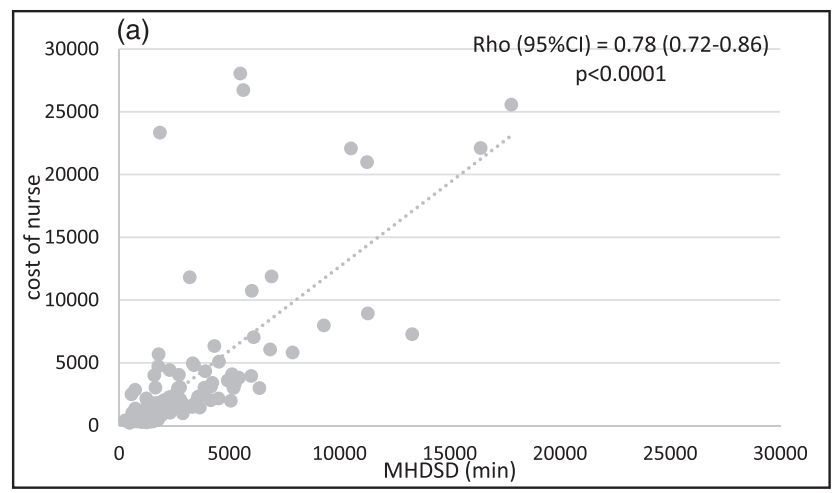

FIG URE 2 Correlations between Nursing Activities Score (NAS) and Minimum Hospital Summary Nursing Dataset (MHSND) with costs. (a) MHSND; (b) NAS

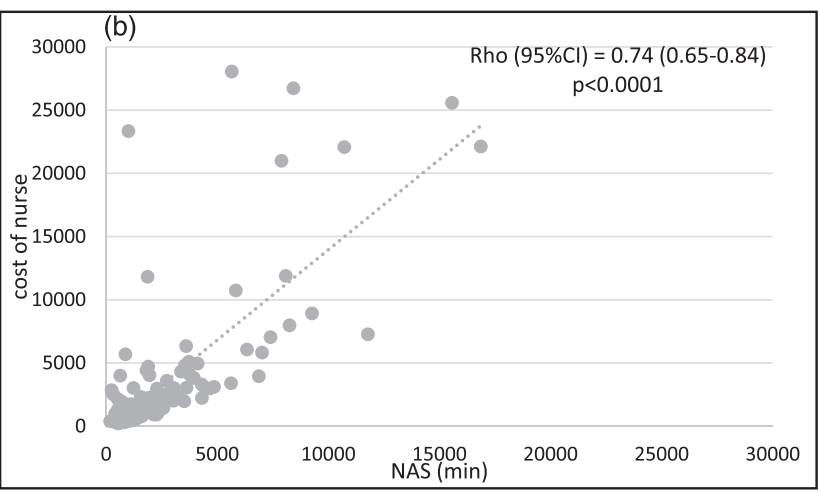

A: MHSND: MHSND: Minimum Hospital Summary Nursing Dataset; B: NAS: Nursing Activities Score.

management of nurses in the ICU (Margadant et al., 2020). Moreover, with the Belgian MHSND scale, it is very difficult to compare the results with other international studies that use the NAS (Padilha et al., 2015).

The cost per stay and of nursing staff in the ICU is difficult to compare with other studies due to the high variability across countries in terms of the cost of care, ICU nurse staffing and non-nursing staff (Stafseth et al., 2018; Tan et al., 2012). On the other hand, both scales show similar results with regard to the correlation analyses of the cost of nursing staff. In the analyses by patient category, there is a strong correlation for urgent surgery patients, but the opposite is true for geriatric patients.

Our study shows that the NAS can be used to assess the cost of nursing staff as have other published studies in the ICU. In addition, the NAS allows an assessment of nursing workload and a comparison with international studies. However, the NAS does not take into 
T A B L E 4 Correlations between NAS and MHSND with costs nursing staff per stay, rho $(95 \% \mathrm{Cl})$

\begin{tabular}{|c|c|c|c|c|}
\hline Characteristics & NAS & $p$ value & MHSND & $p$ value \\
\hline Period 1 & $.75(0.62-0.87)$ & $<.0001$ & $.76(0.66-0.87)$ & $<.0001$ \\
\hline Period 2 & $.72(0.59-0.86)$ & $<.0001$ & $.79(0.69-0.90)$ & $<.0001$ \\
\hline Male & $.82(0.74-0.91)$ & $<.0001$ & $.83(0.75-0.92)$ & $<.0001$ \\
\hline Female & $.62(0.42-0.82)$ & $<.0001$ & $.73(0.59-0.86)$ & $<.0001$ \\
\hline Patients ventilated & $.83(0.67-0.97)$ & $<.0001$ & $.78(0.62-0.94)$ & $<.0001$ \\
\hline Medical & $.68(0.49-0.86)$ & $<.0001$ & $.76(0.65-0.88)$ & $<.0001$ \\
\hline Elective surgery & $.74(0.62-0.87)$ & $<.0001$ & $.76(0.66-0.87)$ & $<.0001$ \\
\hline Urgent surgery & $.84(0.66-0.97)$ & $<.0001$ & $.83(0.58-0.99)$ & $<.0001$ \\
\hline Death & $.69(0.32-0.87)$ & $<.0001$ & $.75(0.35-0.99)$ & $<.0001$ \\
\hline
\end{tabular}

Abbreviations: LOS, length of stay; MHSND, Minimum Hospital Summary Nursing Dataset; NAS, Nursing Activities Score; SAPS 3, The Simplified Acute Physiology Score.

account the skill level of the nurses, although the level of education is important for the quality of care, whereas the MHSND takes this into account in the weighting of minutes (Aiken et al., 2014). We therefore recommend that the Belgian authorities carry out this type of study in several ICUs in the country and eventually replace the MHSND with the NAS, which may be both adequate to assess the funding needs of the ICU in terms of nursing staff but also serve ICU managers.

\section{1 | Limitations}

Our study has limitations. First, this analysis was conducted in a single ICU and only over two 2-week periods. Second, the analysis of nursing staff costs uses, in part, an Omega scale that has not been validated outside France. Finally, another potential problem is the lack of data because of non-documentation by staff for only the NAS as it is not mandatory in Belgium.

\section{5 | CONCLUSION}

In this study, the general nursing funding scale in Belgium is strongly correlated with the nursing workload for the whole ICU stay, but this correlation is moderate per ICU Day. In contrast, both scales showed a good correlation with ICU nursing costs. Further multicenter studies in Belgium are needed to possibly modify the funding of ICU nurses.

\section{6 | IMPLICATIONS FOR NURSING MANAGEMENT}

In Belgium, a general funding scale for nurses does not allow for an assessment of the nursing workload in the ICU. The NAS is strongly correlated with the cost of nursing staff in the ICU. The authors recommend that the Belgian authorities carry out this type of study in several ICUs in the country and eventually replace the general funding scale for nurses with the NAS.

\section{ACKNOWLEDGEMENT}

The authors acknowledge the contribution of a medical writer, Sandy Field, $\mathrm{PhD}$, to the preparation of this manuscript.

\section{CONFLICT OF INTEREST}

The authors declare that they have no conflicts of interest.

\section{ETHICAL APPROVAL}

This study was approved by the University Libre de Bruxelles ethics committee on 19 November 2018, with reference: P2018/559 and by that of the hospital on 19 December 2018, with reference P18/67_28/11.

\section{DATA AVAILABILITY STATEMENT}

Authors do not wish to share the data.

\section{ORCID}

Arnaud Bruyneel (D) https://orcid.org/0000-0002-0432-9474

\section{REFERENCES}

Aiken, L. H., Sloane, D. M., Bruyneel, L., van den Heede, K., Griffiths, P., Busse, R., Diomidous, M., Kinnunen, J., Kózka, M., Lesaffre, E., McHugh, M. D., Moreno-Casbas, M. T., Rafferty, A. M., Schwendimann, R., Scott, P. A., Tishelman, C., van Achterberg, T., \& Sermeus, W. (2014). Nurse staffing and education and hospital mortality in nine European countries: A retrospective observational study. The Lancet, 383(9931), 1824-1830. https://doi.org/10.1016/ S0140-6736(13)62631-8

Bittner, M.-I., Donnelly, M., van Zanten, A. R., Andersen, J., Guidet, B., Trujillano Cabello, J., Gardiner, S., Fitzpatrick, G., Winter, B., Joannidis, M., \& Schmutz, A. (2013). How is intensive care 
reimbursed? A review of eight European countries. Annals of Intensive Care, 3(1), 37. https://doi.org/10.1186/2110-5820-3-37

Blin, F., Fraisse, F., \& Brivet, F. (1990). La charge en soins de réanimation: Evaluation de l'échelle Omega à partir d'une enquête multicentrique. Reanimation Soins Intensifs Medecine D'urgence, 6(5), 341-349.

Bruyneel, A., Guerra, C., Tack, J., Droguet, M., Maes, J., \& Miranda, D. R. (2018). Traduction sémantique en français et implémentation du Nursing Activities Score en Belgique. Médecine Intensive Réanimation, 27(3), 260-272. https://doi.org/10.3166/rea-2018-0029

Bruyneel, A., Smith, P., Tack, J., \& Pirson, M. (2021). Prevalence of burnout risk and factors associated with burnout risk among ICU nurses during the COVID-19 outbreak in French speaking Belgium. Intensive \& Critical Care Nursing, 103059. https://doi.org/10.1016/j.iccn.2021. 103059

Bruyneel, A., Tack, J., Droguet, M., Maes, J., Wittebole, X., Miranda, D. R., \& Pierdomenico, L. D. (2019). Measuring the nursing workload in intensive care with the nursing activities score (NAS): A prospective study in 16 hospitals in Belgium. Journal of Critical Care, 54, 205-211. https://doi.org/10.1016/j.jcrc.2019.08.032

Debergh, D. P., Myny, D., van Herzeele, I., van Maele, G., Miranda, D. R., \& Colardyn, F. (2012). Measuring the nursing workload per shift in the ICU. Intensive Care Medicine, 38(9), 1438-1444. https://doi.org/10. 1007/s00134-012-2648-3

Driscoll, A., Grant, M. J., Carroll, D., Dalton, S., Deaton, C., Jones, I., Lehwaldt, D., McKee, G., Munyombwe, T., \& Astin, F. (2018). The effect of nurse-to-patient ratios on nurse-sensitive patient outcomes in acute specialist units: A systematic review and meta-analysis. European Journal of Cardiovascular Nursing, 17(1), 6-22. https://doi. org/10.1177/1474515117721561

Durant, G., Leclercq, P., \& Pirson, M. (2021). Le financement des hôpitaux et de l'activité médicale: Panorama international et principes méthodologiques. Mardaga supérieur.

Greaves, J., Goodall, D., Berry, A., Shrestha, S., Richardson, A., \& Pearson, P. (2018). Nursing workloads and activity in critical care: A review of the evidence. Intensive \& Critical Care Nursing, 48, 10-20. https://doi.org/10.1016/j.iccn.2018.06.002

Hoogendoorn, M. E., Margadant, C. C., Brinkman, S., Haringman, J. J., Spijkstra, J. J., \& de Keizer, N. F. (2020). Workload scoring systems in the intensive care and their ability to quantify the need for nursing time: A systematic literature review. International Journal of Nursing Studies, 101, 103408. https://doi.org/10.1016/j.jpurstu.2019. 103408

Kilic, M., Yuzkat, N., Soyalp, C., \& Gulhas, N. (2019). Cost analysis on intensive care unit costs based on the length of stay. Turkish Journal of Anaesthesiology and Reanimation, 47(2), 142-145. https://doi.org/10. 5152/TJAR.2019.80445

Lucchini, A., de Felippis, C., Elli, S., Schifano, L., Rolla, F., Pegoraro, F., \& Fumagalli, R. (2014). Nursing activities score (NAS): 5 years of experience in the intensive care units of an Italian University hospital. Intensive \& Critical Care Nursing, 30(3), 152-158. https://doi.org/10. 1016/j.iccn.2013.10.004

Margadant, C., Wortel, S., Hoogendoorn, M., Bosman, R., Spijkstra, J. J., Brinkman, S., \& de Keizer, N. (2020). The nursing activities score per nurse ratio is associated with in-hospital mortality, whereas the patients per nurse ratio is not*. Critical Care Medicine, 48(1), 3-9. https://doi.org/10.1097/CCM.0000000000004005

McHugh, M. D., Aiken, L. H., Sloane, D. M., Windsor, C., Douglas, C., \& Yates, P. (2021). Effects of nurse-to-patient ratio legislation on nurse staffing and patient mortality, readmissions, and length of stay: A prospective study in a panel of hospitals. The Lancet, S0140673621007686. https://doi.org/10.1016/S0140-6736(21) 00768-6, 1905, 1913

Miranda, D. R., Nap, R., de Rijk, A., Schaufeli, W., \& lapichino, G. (2003). Nursing activities score. Critical Care Medicine, 31(2), 374-382. https://doi.org/10.1097/01.CCM.0000045567.78801.CC
Murphy, A., Griffiths, P., Duffield, C., Brady, N. M., Scott, A. P., Ball, J., \& Drennan, J. (2021). Estimating the economic cost of nurse sensitive adverse events amongst patients in medical and surgical settings. Journal of Advanced Nursing, jan.14860, 3379-3388. https://doi.org/ 10.1111/jan.14860

Myny, D., de Bacquer, D., van Hecke, A., Beeckman, D., Verhaeghe, S., \& van Goubergen, D. (2014). Validation of standard times and influencing factors during the development of the workload indicator for nursing. Journal of Advanced Nursing, 70(3), 674-686. https://doi. org/10.1111/jan.12232

Oliveira, E. M., Secco, L. M. D., de Figueiredo, W. B., Padilha, K. G., \& Secoli, S. R. (2019). Nursing activities score and the cost of nursing care required and available. Revista Brasileira de Enfermagem, 72(suppl 1), 137-142. https://doi.org/10.1590/0034-7167-2017-0655

Padilha, K. G., Stafseth, S., Solms, D., Hoogendoom, M., Monge, F. J. C., Gomaa, O. H., Giakoumidakis, K., Giannakopoulou, M., Gallani, M. C., Cudak, E., de Nogueira, L. S., Santoro, C., de Sousa, R. C., Barbosa, R. L., \& dos Miranda, D. R. (2015). Nursing activities score: An updated guideline for its application in the intensive care unit. Revista Da Escola de Enfermagem Da USP, 49(spe), 131-137. https:// doi.org/10.1590/S0080-623420150000700019

Pirson, M., Delo, C., di Pierdomenico, L., Laport, N., Biloque, V., \& Leclercq, P. (2013). Variability of nursing care by APR-DRG and by severity of illness in a sample of nine Belgian hospitals. BMC Nursing, 12(1), 26. https://doi.org/10.1186/1472-6955-12-26

Pirson, M., \& Leclercq, P. (2014). Un projet pilote d'évaluation des coûts par pathologie, le projet PACHA. Healthcare Executive, 78, 12-24. https://www.healthcare-executive.be/fr/actualites/medical/unprojet-pilote-d-rsquo-evaluation-des-couts-par-pathologie-le-projetpacha.html

Reis Miranda, D., \& Jegers, M. (2012). Monitoring costs in the ICU: A search for a pertinent methodology: Monitoring costs in the ICU. Acta Anaesthesiologica Scandinavica, 56(9), 1104-1113. https://doi.org/ 10.1111/j.1399-6576.2012.02735.x

Ricci de Araújo, T., Papathanassoglou, E., Gonçalves Menegueti, M., Grespan Bonacim, C. A., Lessa do Valle Dallora, M. E., Carvalho Jericó, M., Basile-Filho, A., \& Laus, A. M. (2021). Critical care nursing service costs: Comparison of the top-down versus bottom-up microcosting approach in Brazil. Journal of Nursing Management, jonm.13313. https://doi.org/10.1111/jonm.13313

Schober, P., Boer, C., \& Schwarte, L. A. (2018). Correlation coefficients: Appropriate use and interpretation. Anesthesia \& Analgesia, 126(5), 1763-1768. https://doi.org/10.1213/ANE.0000000000002864

Sermeus, W., Gillet, P., Tambeur, W., Gillain, D., Grietens, J., Laport, N., Michiels, D., Thonon, O., vanden Boer, G., van Herck, P., Swartenbroekx, N., \& Ramaekers, D. (2007). Financement des soins infirmiers hospitaliers (KCE reports 53B (D/2006/10.273/07); Health Services Research (HSR). Bruxelles: Centre Fédéral d'expertise Des Soins de Santé (KCE).

SPF Santé publique. (2017). MANUEL DE CODAGE - Des Données Infirmières du Résumé Hospitalier Minimum DI-RHM. https://www. health.belgium.be/sites/default/files/uploads/fields/fpshealth_ theme_file/manuel_de_codage_di-rhm_-_septembre_2017_-version_officielle_2.0.pdf

Stafseth, S. K., Tønnessen, T. I., \& Fagerström, L. (2018). Association between patient classification systems and nurse staffing costs in intensive care units: An exploratory study. Intensive \& Critical Care Nursing, 45, 78-84. https://doi.org/10.1016/j.iccn.2018.01.007

Stephani, V., Quentin, W., van den Heede, K., van de Voorde, C., \& Geissler, A. (2018). Payment methods for hospital stays with a large variability in the care process (KCE Reports 302; D/2018/10.273/36). http://kce.fgov.be/content/about-copyrightsfor-kce-publications

Tan, S. S., Bakker, J., Hoogendoorn, M. E., Kapila, A., Martin, J., Pezzi, A., Pittoni, G., Spronk, P. E., Welte, R., \& Hakkaart-van Roijen, L. (2012). 
Direct cost analysis of intensive care unit stay in four European countries: Applying a standardized costing methodology. Value in Health, 15(1), 81-86. https://doi.org/10.1016/j.jval.2011.09.007

Utilisation de l'indice de gravité simplifié et du système Omega. (1986). Utilisation de l'indice de gravité simplifié et du système Omega. Reanimation Soins Intensifs Medecine D'urgence, 2(4), 219-221.

van den Heede, K., Bruyneel, L., Beeckmans, D., Boon, N., Bouckaert, N., Cornelis, J., Dossche, D., van de Voorde, C., \& Sermeus, W. (2019). Safe nurse staffing levels in acute hospitals. Health Services Research (HSR) Brussels: Belgian Health Care Knowledge Centre (KCE). KCE Reports, 325. D/2019/10.273/75
How to cite this article: Bruyneel, A., Maes, J., Di

Pierdomenico, L., Tack, J., Bogaert, M., Leclercq, P., \& Pirson,

M. (2022). Associations between two nursing workload scales and the cost of intensive care unit nursing staff: A

retrospective study of one Belgian hospital. Journal of Nursing

Management, 1-9. https://doi.org/10.1111/jonm.13544 